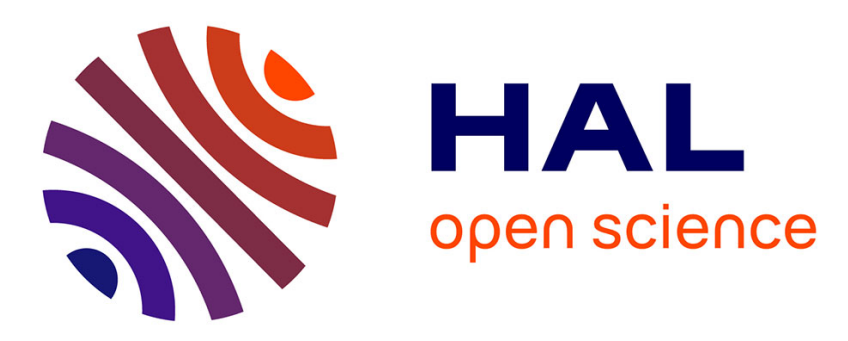

\title{
Sex-Mediated Response to the Beta-Blocker Landiolol in Sepsis
}

\author{
C. Mathieu, Martine Desrois, Frank Kober, Nathalie Lalevee, Carole Lan, \\ Natacha Fourny, Magali Iché-Torres, Thi Thom Tran, Linh Thuy Lê, Mervyn \\ Singer, et al.
}

\section{To cite this version:}

C. Mathieu, Martine Desrois, Frank Kober, Nathalie Lalevee, Carole Lan, et al.. Sex-Mediated Response to the Beta-Blocker Landiolol in Sepsis. Critical Care Medicine, 2018, 46 (7), pp.e684-e691. 10.1097/CCM.0000000000003146 . hal-01844468

\section{HAL Id: hal-01844468 \\ https://hal.science/hal-01844468}

Submitted on 22 Jan 2019

HAL is a multi-disciplinary open access archive for the deposit and dissemination of scientific research documents, whether they are published or not. The documents may come from teaching and research institutions in France or abroad, or from public or private research centers.
L'archive ouverte pluridisciplinaire HAL, est destinée au dépôt et à la diffusion de documents scientifiques de niveau recherche, publiés ou non, émanant des établissements d'enseignement et de recherche français ou étrangers, des laboratoires publics ou privés. 


\section{Sex-mediated response to the beta-blocker landiolol in sepsis:}

\section{an experimental, randomized study}

Calypso Mathieu, ${ }^{1,2}$ Martine Desrois, ${ }^{2}$ Frank Kober, ${ }^{2}$ Nathalie Lalevée, ${ }^{3}$ Carole Lan, ${ }^{2}$ Natacha Fourny ${ }^{2}$, Magali Iché-Torres, ${ }^{3}$ Thi Thom Tran, ${ }^{3}$, Linh Thuy Lê, ${ }^{3}$ Mervyn Singer, ${ }^{4}$ Jean-Louis

$$
\text { Mege, }{ }^{5} \text { Monique Bernard, }{ }^{2} \text { Marc Leone }{ }^{1,5}
$$

1. Aix Marseille Univ, Service d'anesthésie et de réanimation, Hôpital Nord, Assistance Publique Hôpitaux de Marseille, Marseille, France

2. Aix-Marseille Univ, CNRS, CRMBM,, Marseille, France

3. Aix-Marseille Univ, INSERM, TAGC, UMR 1090, Marseille, France

4. University College London, 4919, Bloomsbury Inst of Intensive Care Medicine, Cruciform Building, London, United Kingdom of Great Britain and Northern Ireland

5. CNRS UMR 7278, IRD198, INSERM U1095, Institut Hospitalier Universitaire Méditerranée-Infection, AixMarseille Université, Marseille , France

\section{Corresponding author:}

Marc Leone, MD, PhD

Service d'anesthésie et de réanimation

Hopital Nord

Chemin des Bourrely

139015 Marseille, France

marc.leone@ap-hm.fr

Conflicts of Interest and Source of Funding: The study was funded by Fondation pour la Recherche Médicale (DEA 20150633224), AOP Orphan, Lions Club Marseille Doyen and France Life Imaging (grant ANR-11-INBS0006). 


\section{ABSTRACT}

Objective: To investigate any gender effect of the beta1-adrenergic blocker, landiolol, on cardiac performance and energy metabolism in septic rats, and to explore the expression of genes and proteins involved in this process.

Design: Randomized animal study.

Setting: University research laboratory.

Subjects: Male and female Wistar rats.

Interventions: One hour after cecal ligation and puncture (CLP), male and female rats were randomly allocated to the following groups: sham male, CLP male, CLP + landiolol male, sham female, CLP female and CLP + landiolol female. Cardiac magnetic resonance imaging was carried out 18 hours after CLP to assess in-vivo cardiac function. Ex-vivo cardiac function measurement and 31P magnetic resonance spectroscopy were subsequently performed using an isovolumic isolated heart preparation. Finally, we assessed cardiac gene and protein expression.

Measurements and Main Results: In males, landiolol increased indexed stoke volume (SVi) by reversing the indexed end-diastolic volume (EDVi) reduction without affecting left ventricle ejection fraction (LVEF). In females, landiolol did not increase SVi and EDVi, but decreased LVEF. Landiolol had no effect on ex-vivo cardiac function and on high-energy phosphate compounds. The effect of landiolol on the gene expression of NPR3 and on protein expression of pAKT:AKT ratio and eNOS was different in males and females.

Conclusion: Landiolol improved the in-vivo cardiac performance of septic male rats while deleterious effects were reported in females. Expression of NPR3, pAKT:AKT and eNOS are 
signaling pathways to investigate to better understand the sex differences in sepsis.Keywords: sepsis, sex differences, adrenergic beta-blockers, cardiac dysfunction, magnetic resonance imaging, energy metabolism 


\section{INTRODUCTION}

The adrenergic system plays a key role in septic shock (1). However, prolonged and excessive adrenergic stimulation is cardiotoxic (2). In critically ill patients, the administration of dobutamine to maintain an elevated cardiac index is associated with increased mortality (3). In a previous animal study, we showed that use of a pure ß-agonist led to hypertrophic cardiac failure (4). In experimental models of sepsis esmolol, a selective ß1-adrenergic blocker, improved cardiac contractility, stroke volume (SV) and vascular responsiveness to norepinephrine (5-7). In patients in established septic shock, Morelli et al. also showed that esmolol infusion reduced heart rate (HR), increased SV and decreased norepinephrine requirements (8).

Experimentally, the host response to an inflammatory insult differs according to sex $(9,10)$. We showed that male mice were at higher risk of developing severe forms of acute $Q$ fever $(11,12)$. In an endotoxin murine model, ex-vivo cardiac performance was more impaired (10). In humans, sex seems to affect the response to ß-blockers $(13,14)$.

To our knowledge, in sepsis, the gender-dependent response to ß-blockers remains undetermined. Our hypothesis was that beta-blockade would prevent cardiac dysfunction in males but not in females. Landiolol has a high affinity for ß1-adrenergic receptors (ß1-AR), with a ß1: ß2 ratio of 255, compared to 33 for esmolol (15).

We thus assessed the sex-dependent effects of landiolol on in-vivo cardiac performance during sepsis using magnetic resonance imaging (MRI). We further evaluated the effects of landiolol on ex-vivo cardiac performance, energy metabolism and oxidative stress on an isolated perfused heart preparation. Finally, we investigated the expression of candidate 
genes involved in various pathways and known to be involved in cardiac function to elicit potential mechanisms of action during sepsis.

\section{MATERIALS AND METHODS}

Animals and cecal ligation and puncture model

Male and female Wistar rats (9-12 weeks old, Charles River, Saint-Germain sur l'Arbresle, France) were housed for a 5-7-day acclimatization period in a temperature and lightcontrolled room with free access to water and food. All animal procedures were conducted in accordance with national Guidelines for Care and Use of Laboratory Animals in conformity with the 2010/63 EU directive and with the approval of the Institutional Animal Care Committee of Aix-Marseille University (APAFIS\#3746-201601221813985). The anesthetic and surgical procedure is reported in Supplemental Digital Content 1.

\section{Experimental protocol}

Supplemental Digital Content 2 summarizes experimental protocol. One hour after cecal ligation and puncture (CLP), males and females were randomized to receive landiolol (AOP Orphan, Vienna, Austria) diluted in $\mathrm{n}$-saline and infused at $0.1 \mathrm{mg} / \mathrm{kg} / \mathrm{min}$ or $\mathrm{n}$-saline (10 $\mathrm{mL} / \mathrm{kg} / \mathrm{h}$ ). The infusion volume was similar in all groups. Six groups were studied: sham male $(n=6)$, CLP male $(n=8), \operatorname{CLP}+$ landiolol male $(n=7)$, sham female $(n=7)$, CLP female $(n=8)$ and $\mathrm{CLP}+$ landiolol female $(\mathrm{n}=7)$. Eighteen hours after surgery, rats were anesthetized using 1.5 $2 \%$ isoflurane. The caudal ventral artery was cannulated (24-gauge catheter) for blood 
pressure recording (TruWave pressure transducer, Edwards Lifesciences, Irvine, CA). Systolic blood pressure (SBP), diastolic blood pressure (DBP) and mean blood pressure (MBP) were recorded at $\mathrm{H} 18$. Body weight variations between $\mathrm{HO}$ and $\mathrm{H} 18$ were measured. Cardiac MRI was performed 18 hours after CLP to assess in-vivo cardiac function (cine-MRI) and myocardial perfusion (Arterial spin labeling, ASL MRI). Ex-vivo cardiac function measurement and 31P magnetic resonance spectroscopy (MRS) were performed at H19 using isolated heart preparation. At $\mathrm{H} 20$, hearts were frozen for subsequent biochemical analyses and quantification of gene expression.

\section{MRI assessment of in-vivo cardiac function}

MRI was performed 18 hours after CLP, immediately after arterial cannulation. During MRI, inhalation anesthesia was maintained with $1.4-1.8 \%$ isoflurane in $1.5 \mathrm{~L} / \mathrm{min}$ oxygen continuously delivered through a face mask. Details are provided in Supplemental Digital Content 1.

End-diastolic volume (EDV), end-systolic volume (ESV), stroke volume (SV), left ventricle ejection fraction (LVEF), mean wall thicknesses in diastole (WTd) and systole (WTs), and systolic wall thickening (WTn) were calculated from the volume measurements, as described previously (16). Cardiac output (CO) was calculated as CO=HRxSV. EDV (EDVi), ESV (ESVi), SV (SVi) and cardiac index $(\mathrm{Cl})$ were indexed to weight.

In-vivo myocardial perfusion was quantified using the cine-ASL technique, as previously described (17). Image analyses were performed using a home-made program running in an IDL environment which generated absolute myocardial blood flow (MBF) maps. MBF was 
determined by manually delineating regions of interest in the entire left ventricular myocardium on the corresponding MBF maps.

Isolated rat heart preparation for ex vivo cardiac function and 31P MRS

At $\mathrm{H} 19$, rats were anesthetized by intraperitoneal injection of $50 \mathrm{mg} / \mathrm{kg}$ pentobarbital sodium. Blood samples were taken through the arterial catheter and immediately centrifuged. After bilateral thoracotomy, the heart was quickly excised and mounted onto an isolated perfused heart apparatus according to the Langendorff method (4). Details are provided in Supplemental Digital Content 1.

A latex balloon was introduced into the left ventricle to evaluate ex vivo cardiac function. End-diastolic pressure was set to $10 \mathrm{mmHg}$. Left ventricular developed pressure (LVDP) and HR were monitored (18). The rate-pressure product (RPP), calculated as the product of LVDP and HR, was used as an index of cardiac function. Coronary flow was measured by timed collection of the coronary venous effluent, and indexed by weight of heart.

The perfused rat heart was placed in a $20-\mathrm{mm}$ MR sample tube and inserted into a 31P probe seated in the bore of a superconducting wide-bore (89-mm) 4.7-T magnet (Oxford Instruments, Oxford, UK) interfaced with a Bruker-Nicolet WP-200 spectrometer (Bruker, Karlsruhe, Germany). The appropriate conditions for acquiring 31P magnetic resonance spectra and the quantification of phosphorus metabolites have been detailed previously $(4,18)$. Details are provided in Supplemental Digital Content 1. 
Ribonucleic acid (RNA) extraction and quantitative reverse transcription-polymerase chain reaction (RT-PCR), Immunoblotting and Western-blot, and Biochemical analyses in plasma For more details, see Supplemental Digital Content 1.

\section{Statistical analysis}

Data are expressed as means \pm standard error of the mean (SEM). After statistical evaluation, the number of rats required was 6 per group to show a 30\% increase in SV by landiolol with a power and an alpha risk of $80 \%$ and 5\%, respectively. Significant differences between groups were determined using two-way analysis of variance (ANOVA) followed by Sidak post-hoc testing with Graphpad Prism software (Graphpad Prism 7.0, La Jolla, CA, USA). A p value $<0.05$ was considered statistically significant. Isolated heart preparation data from 6 rats (CLP male $(n=2)$, sham female $(n=2)$, CLP female $(n=2)$ ) were not determined due to traumatic removal.

\section{RESULTS}

Effects of CLP and landiolol on weight variation and temperature after 18 hours

In both males and females, CLP was associated with weight gain ( $p<0.001$ for both) and hypothermia ( $p<0.001$ and $p=0.003$, respectively), as compared with sham animals (Table 1$)$. The CLP+landiolol male group had a lower weight gain $(p=0.001)$ and less hypothermia $(p=0.015)$ than untreated CLP males. In septic females, landiolol did not impact upon either weight or temperature. 
Effects of CLP and landiolol on hemodynamic variables after 18 hours

Landiolol decreased HR from $404 \pm 9$ to $330 \pm 11$ b/min in septic males $(p<0.001)$, and from $388 \pm 14$ to $345 \pm 14 \mathrm{~b} / \mathrm{min}$ in septic females $(p=0.024)$ (Table 1$)$. Landiolol did not affect blood pressure in males, whereas DBP and MBP decreased in landiolol-treated females $(p=0.002$; $\mathrm{p}=0.013)$. Plasma lactate concentrations were similar in all groups.

Effects of CLP and landiolol on in vivo cardiac function and perfusion using MRI

Cardiac MRI variables are reported in Table 2 and indexed parameters in Figure 1. In males, SVi, $\mathrm{Cl}$ and EDVi decreased after CLP ( $p<0.001$ vs. sham) whereas only $\mathrm{Cl}$ and EDVi decreased in females ( $p=0.020$ and $p=0.046$ vs. sham).

In septic males, landiolol administration increased SVI, ESVi and EDVi (all $p<0.05$ ) compared with untreated animals (Figure 1). LVEF and systolic wall thickening (sWtn) were similar between groups (Table 2). In females, landiolol increased ESVi $(p<0.001)$ and decreased LVEF $(p<0.001)$ and sWtn $(p=0.009)$ compared to untreated animals. Myocardial blood flow was not different between groups.

Effects of CLP and landiolol on ex vivo cardiac function in the isolated heart preparation Table 3 shows myocardial function and coronary flow in the isolated rat heart preparation at H19. Heart weight to body weight ratios were similar between groups. CLP decreased LVDP and RPP in both males and females (all $p<0.05$ ). LVDP, RPP and coronary flow index were similar between landiolol-treated and untreated CLP groups.

\footnotetext{
${ }^{31} \mathrm{P}$ MRS measurements of myocardial energy metabolism and $\mathrm{pHi}$
} 
High-energy phosphate compounds and pHi measured by 31P MRS are shown in Supplemental Digital Content 3. Data represent the average of the 4 last spectra. Phosphocreatine (PCr), adenosine triphosphate (ATP), phosphomonoesters (PME), inorganic phosphate $(\mathrm{Pi})$, intracellular $\mathrm{pH}(\mathrm{pHi})$ and $\mathrm{PCr} / \mathrm{ATP}$ ratio were similar in males and females.

\section{Effects of CLP and landiolol on myocardial gene expression}

Genes encoding signaling proteins known for their role in cardiac and immune function are detailed in Supplemental Digital Content 4. IL-10 increased in males and females after CLP ( $p<0.001$ and $p<0.01$, respectively), without any effect of landiolol. IL-15 was lower in CLP females ( $p=0.01$ vs. sham) and landiolol reversed this effect ( $p=0.032$ vs. CLP female group). IL-1ra was higher in the CLP female group compared to sham $(p=0.016)$ and landiolol attenuated this effect. These variations were not found in males. More details are available in Supplemental Digital Content 1.

CLP decreased NPR3 (natriuretic peptide receptor 3) transcript levels in both males and females $(p<0.001)$. Landiolol reversed this decrease in males ( $p>0.05$ vs. sham males) but not in females ( $p=0.002$ vs. sham females). In males, no effect of CLP was observed on transcript levels of ryanodine receptor 2 (RYR2). In females, RYR2 expression was decreased after CLP with landiolol reversing this effect.

\section{Effects of CLP and landiolol on myocardial protein expression}

In CLP males, the PAKT:AKT ratio decreased ( $p=0.04$ vs. sham males) (Figure 2 ) and this was unaffected by landiolol. In CLP females, the PAKT:AKT ratio was similar to sham and landiolol increased this ratio ( $p=0.004$ vs. CLP females) (Figure 2). In males, eNOS expression was higher in CLP than in sham ( $p=0.004)$. Landiolol attenuated this effect (Figure 2). In females, 
CLP and landiolol did not affect eNOS expression, as compared with sham females. As compared with males, eNOS expression was higher in sham $(p=0.028)$ and landiolol females $(p=0.026)$.

\section{DISCUSSION}

To our knowledge, this is the first comparison of response to ß-blockers in males and females with sepsis-induced myocardial dysfunction. Our results highlight disparities between the sexes. While landiolol improved cardiac performance in the septic males, it was associated with a reduction in LVEF and sWtn in the septic females. A strength of our study relies on the assessment of cardiac function using MRI, providing an in-vivo assessment of cardiac function in addition to ex-vivo evaluation. At variance with previous models based on the isolated perfused heart $(7,19,20)$, the in-vivo study incorporates heart-vessel interactions in the analysis of cardiac performance. As in septic patients, ß-blockers were associated with reduced ventriculo-arterial decoupling $(21,22)$, underlining the clinical relevance of the model.

In males, landiolol improved SVi, probably by reversing the reduction in EDVi after CLP, but without any significant effect on LVEF, $\mathrm{Cl}$ and $\mathrm{Wtn}$. This finding is in line with previous experimental studies $(7,20)$. Using a conductance catheter in male rats undergoing CLP, Kimmoun et al. also found improved myocardial function with ß-blockers (5). A metaanalysis has shown an association between diastolic dysfunction and mortality in septic patients so this may represent an important protective effect of ß-blockers (23).

In contrast to septic males, septic females however maintained SVi at the level of sham females. Landiolol did not improve SVI, $\mathrm{Cl}$ and EDVi but decreased LVEF and sWtn. Cardiac performance ex-vivo was more impaired in males than in females after endotoxin 
administration (10). In our in-vivo study, landiolol improved cardiac performance in septic males but seemed deleterious in females. While not yet formally examined in septic patients, women undergoing high-risk surgery did not benefit from perioperative ß-blockers, a finding at variance with men (24). With exercise, the hemodynamic response to metoprolol in women resulted in a larger reduction of HR and blood pressure (25). Lindenfeld et al. showed that sex affects age-related ß-AR downregulation in normal human ventricles, suggesting an effect of sex hormones (26). Downregulation of ß-AR by estrogen may be a protective strategy in the case of hyperstimulation (27-29). The interaction between estrogen-receptors and ß-AR may explain the sex-dependent response to ß-blockers (29).

In our model, septic myocardial dysfunction was more pronounced in males. In an experimental model of fluid resuscitated sepsis, Khaliq et al. compared the hemodynamic effects of esmolol in predicted survivors and predicted non-survivors in a fecal peritonitis model using male rats only (30). In the predicted non-survivors, esmolol infusion was associated with an increase in SV, while CO remained stable, whereas SV and CO decreased with esmolol in predicted survivors. Thus, the underlying severity of the septic myocardial dysfunction may impact upon the response to ß-blockers. In our study landiolol did not alter myocardial blood perfusion nor indexed coronary flow in either gender. In septic patients, coronary flow is typically normal or increased (31).

Mitochondria are the predominant generators of ATP in most cell types. Cardiomyocyte mitochondrial dysfunction is characterized by ultrastructural damage, decreased activity of electron transport chain enzyme complexes, and an increase in reactive oxygen species production (32-34). In sepsis, mitochondrial dysfunction is associated with the degree of organ failure (35). Here, sepsis did not affect high-energy phosphate compounds and pHi. Myocardial ATP content remained unchanged while LVDP decreased. In another model of 
sepsis using 31P MRS, energetic parameters were also stable despite alterations in cardiac function $(36,37)$, suggesting that energetic metabolism is not limiting cardiac function in sepsis. Conversely, using biochemical analyses, Escames et al. however found a decrease in ATP production in hearts from septic mice (38).

There was a sex-dependent effect on expression of genes involved in the inflammatory response in our septic animals. The lack of difference in TNF, IL-1 beta and IL-6 may reflect the late timepoint of collection of cardiac tissue (39). However, in line with a previous study, landiolol did not seem to interacting with most inflammatory pathways (40). Of note, landiolol acts predominantly on ß1-AR. As reported elsewhere (1), the mechanism of ß1-AR activation on inflammatory pathways remains unclear, and at variance with that of B2-AR activation.

NPR3 has an anti-apoptosis role and protects cardiomyocytes (41). NPR3 decreased in both sexes after CLP and landiolol could reverse this effect in the septic males only. In our model, we found a different expression of eNOS and PAKT:AKT in males and females. Females have a reduced susceptibility to cardiac ischemic injury with NO generation playing a pivotal protective role $(42,43)$. In a model of endotoxemia, the protection of the female heart was associated with the AKT/eNOS pathway (44). Kimmoun et al. also showed an increase in AKT and eNOS phosphorylation with esmolol in a model of sepsis (5). These pathways may thus be implicated in the different response to beta-blockers according to sex.

Our study has several limitations. The difference between the weight of males and females was significant; males initially weighed 1.4 times the female weight. Landiolol was administered according to the weight of each animal and each variable was adjusted to weight. 
The ultra-short half-life of landiolol can have resulted in low tissue concentrations in the isolated heart (15). The isolated heart also removes the effects of circulating myocardial depressant factors that are implicated in sepsis-induced myocardial dysfunction so this may not necessarily reflect the in-vivo situation (45). Another limitation is the choice of the intravenous dose of landiolol, which was infused at a fixed dose. In our study, blood pressure remained constant in males but decreased in females. The dose could be adapted to an individual animal's response, since the pharmacokinetics of ß-blockers depends on gender and age (25). Another limitation is that our study did not assess the baseline response to landiolol. Landiolol is hydrolysed to an inactivate metabolite by esterases, which activities are higher in female rats than in male rats (46). Moreover, the response to general anesthesia may be sex-mediated (47) and hypothermia may affect the cardiac effects of $ß$ blockers (48). Our septic rats did not develop profound hypotension thus the role of norepinephrine was not assessed, requiring future studies. Furthermore, we studied young rats; most patients with sepsis are however postmenopausal so our results may not necessarily reflect responses in older females.

\section{CONCLUSION}

Our model confirms that cardiac function was more impaired in septic males compared to their female counterparts. Landiolol ameliorated the cardiac dysfunction in males, particularly in relation to an improvement in diastolic function. Landiolol however produced deleterious effects in females. Phosphorylation of AKT and altered expression of eNOS and NPR3 are potential signaling pathways that merit further investigation in order to better understand sex differences. 


\section{References}

1. de Montmollin E, Aboab J, Mansart A, Annane D. Bench-to-bedside review: Betaadrenergic modulation in sepsis. Crit Care Lond Engl. 2009;13(5):230.

2. Dünser MW, Hasibeder WR. Sympathetic overstimulation during critical illness: adverse effects of adrenergic stress. J Intensive Care Med. 2009 Oct;24(5):293-316.

3. Hayes MA, Timmins AC, Yau EH, Palazzo M, Hinds CJ, Watson D. Elevation of systemic oxygen delivery in the treatment of critically ill patients. N Engl J Med. 1994 Jun 16;330(24):1717-22.

4. Desrois M, Kober F, Lan C, Dalmasso C, Cole M, Clarke K, et al. Effect of isoproterenol on myocardial perfusion, function, energy metabolism and nitric oxide pathway in the rat heart - a longitudinal MR study. NMR Biomed. 2014 May;27(5):529-38.

5. Kimmoun A, Louis H, Al Kattani N, Delemazure J, Dessales N, Wei C, et al. $\beta 1$-Adrenergic Inhibition Improves Cardiac and Vascular Function in Experimental Septic Shock. Crit Care Med. 2015 Sep;43(9):e332-40.

6. Aboab J, Sebille V, Jourdain M, Mangalaboyi J, Gharbi M, Mansart A, et al. Effects of esmolol on systemic and pulmonary hemodynamics and on oxygenation in pigs with hypodynamic endotoxin shock. Intensive Care Med. 2011 Aug;37(8):1344-51.

7. Suzuki T, Morisaki $H$, Serita R, Yamamoto $M$, Kotake $Y$, Ishizaka $A$, et al. Infusion of the beta-adrenergic blocker esmolol attenuates myocardial dysfunction in septic rats. Crit Care Med. 2005 Oct;33(10):2294-301.

8. Morelli A, Ertmer C, Westphal M, Rehberg S, Kampmeier T, Ligges S, et al. Effect of heart rate control with esmolol on hemodynamic and clinical outcomes in patients with septic shock: a randomized clinical trial. JAMA. 2013 Oct 23;310(16):1683-91.

9. Angele MK, Pratschke S, Hubbard WJ, Chaudry IH. Gender differences in sepsis: cardiovascular and immunological aspects. Virulence. 2014 Jan 1;5(1):12-9.

10. Zhu H, Shan L, Peng T. Rac1 mediates sex difference in cardiac tumor necrosis factoralpha expression via NADPH oxidase-ERK1/2/p38 MAPK pathway in endotoxemia. J Mol Cell Cardiol. 2009 Aug;47(2):264-74.

11. Leone M, Honstettre A, Lepidi H, Capo C, Bayard F, Raoult D, et al. Effect of sex on Coxiella burnetii infection: protective role of 17beta-estradiol. J Infect Dis. 2004 Jan 15;189(2):339-45.

12. Textoris J, Ban LH, Capo C, Raoult D, Leone M, Mege J-L. Sex-related differences in gene expression following Coxiella burnetii infection in mice: potential role of circadian rhythm. PloS One. 2010 Aug 13;5(8):e12190. 
13. Kneale BJ, Chowienczyk PJ, Brett SE, Coltart DJ, Ritter JM. Gender differences in sensitivity to adrenergic agonists of forearm resistance vasculature. J Am Coll Cardiol. 2000 Oct;36(4):1233-8.

14. Hart EC, Charkoudian N, Wallin BG, Curry TB, Eisenach J, Joyner MJ. Sex and ageing differences in resting arterial pressure regulation: the role of the $\beta$-adrenergic receptors. J Physiol. 2011 Nov 1;589(Pt 21):5285-97.

15. Iguchi S, Iwamura H, Nishizaki M, Hayashi A, Senokuchi K, Kobayashi K, et al. Development of a highly cardioselective ultra short-acting beta-blocker, ONO-1101. Chem Pharm Bull (Tokyo). 1992 Jun;40(6):1462-9.

16. Kober F, Iltis I, Cozzone PJ, Bernard M. Cine-MRI assessment of cardiac function in mice anesthetized with ketamine/xylazine and isoflurane. Magma N Y N. 2004 Dec;17(36):157-61.

17. Kober F, Iltis I, Izquierdo M, Desrois M, Ibarrola D, Cozzone PJ, et al. High-resolution myocardial perfusion mapping in small animals in vivo by spin-labeling gradient-echo imaging. Magn Reson Med. 2004 Jan;51(1):62-7.

18. Desrois M, Caus T, Belles PM, Dalmasso C, Lan C, Cozzone PJ, et al. Limitation of myocardial and endothelial injury of the rat heart graft after preservation with Centre de Résonance Magnétique Biologique et Médicale (CRMB) solution. Transpl Int Off J Eur Soc Organ Transplant. 2008 Mar;21(3):276-83.

19. Ackland GL, Yao ST, Rudiger A, Dyson A, Stidwill R, Poputnikov D, et al. Cardioprotection, attenuated systemic inflammation, and survival benefit of beta1adrenoceptor blockade in severe sepsis in rats. Crit Care Med. 2010 Feb;38(2):388-94.

20. Hagiwara S, Iwasaka H, Maeda H, Noguchi T. Landiolol, an ultrashort-acting beta1adrenoceptor antagonist, has protective effects in an LPS-induced systemic inflammation model. Shock Augusta Ga. 2009 May;31(5):515-20.

21. Morelli A, Singer M, Ranieri VM, D’Egidio A, Mascia L, Orecchioni A, et al. Heart rate reduction with esmolol is associated with improved arterial elastance in patients with septic shock: a prospective observational study. Intensive Care Med. 2016 Apr 21;

22. Mathieu C, Zieleskiewicz L, Leone M. Beta-blockers in septic shock: a magnifying glass on the relation heart vessel. J Thorac Dis. 2016 Aug;8(8):E802-4.

23. Sanfilippo F, Corredor C, Fletcher N, Landesberg G, Benedetto U, Foex P, et al. Diastolic dysfunction and mortality in septic patients: a systematic review and meta-analysis. Intensive Care Med. 2015 Jun;41(6):1004-13.

24. Matyal R, Mahmood F, Panzica P, Pomposelli F, Park KW, Hamden A, et al. Sex-related differences in outcome after high-risk vascular surgery after the administration of betaadrenergic-blocking drugs. J Cardiothorac Vasc Anesth. 2008 Jun;22(3):354-60. 
25. Luzier AB, Killian A, Wilton JH, Wilson MF, Forrest A, Kazierad DJ. Gender-related effects on metoprolol pharmacokinetics and pharmacodynamics in healthy volunteers. Clin Pharmacol Ther. 1999 Dec;66(6):594-601.

26. Khaliq $W$, Andreis D, Singer M. Beta-blockade in experimental fluid-resuscitated sepsis : acute haemodynamic effects of esmolol differ in predicted survivors and non-survivors.

27. Dhainaut JF, Huyghebaert MF, Monsallier JF, Lefevre G, Dall'Ava-Santucci J, Brunet F, et al. Coronary hemodynamics and myocardial metabolism of lactate, free fatty acids, glucose, and ketones in patients with septic shock. Circulation. 1987 Mar;75(3):533-41.

28. Rudiger A, Singer M. Mechanisms of sepsis-induced cardiac dysfunction. Crit Care Med. 2007 Jun;35(6):1599-608.

29. Smeding L, Plötz FB, Groeneveld ABJ, Kneyber MCJ. Structural changes of the heart during severe sepsis or septic shock. Shock Augusta Ga. 2012 May;37(5):449-56.

30. Cimolai MC, Alvarez S, Bode C, Bugger H. Mitochondrial Mechanisms in Septic Cardiomyopathy. Int J Mol Sci. 2015 Aug 3;16(8):17763-78.

31. Singer $M$. The role of mitochondrial dysfunction in sepsis-induced multi-organ failure. Virulence. 2014 Jan 1;5(1):66-72.

32. Sikes PJ, Zhao P, Maass DL, White J, Horton JW. Sodium/hydrogen exchange activity in sepsis and in sepsis complicated by previous injury: 31P and 23Na NMR study. Crit Care Med. 2005 Mar;33(3):605-15.

33. Solomon MA, Correa R, Alexander HR, Koev LA, Cobb JP, Kim DK, et al. Myocardial energy metabolism and morphology in a canine model of sepsis. Am J Physiol. 1994 Feb;266(2 Pt 2):H757-68.

34. Escames G, López LC, Ortiz F, López A, García JA, Ros E, et al. Attenuation of cardiac mitochondrial dysfunction by melatonin in septic mice. FEBS J. 2007 Apr;274(8):213547.

35. Vincent J-L, Rello J, Marshall J, Silva E, Anzueto A, Martin CD, et al. International study of the prevalence and outcomes of infection in intensive care units. JAMA. 2009 Dec 2;302(21):2323-9.

36. Boyd JH, Forbes J, Nakada T, Walley KR, Russell JA. Fluid resuscitation in septic shock: a positive fluid balance and elevated central venous pressure are associated with increased mortality. Crit Care Med. 2011 Feb;39(2):259-65.

37. Morelli A, Donati A, Ertmer C, Rehberg S, Kampmeier T, Orecchioni A, et al. Microvascular effects of heart rate control with esmolol in patients with septic shock: a pilot study. Crit Care Med. 2013 Sep;41(9):2162-8.

38. Lesur I, Textoris J, Loriod B, Courbon C, Garcia S, Leone M, et al. Gene expression profiles characterize inflammation stages in the acute lung injury in mice. PloS One. $2010 \mathrm{Jul}$ 8;5(7):e11485. 
39. Matsuishi $\mathrm{Y}$, Jesmin S, Kawano S, Hideaki S, Shimojo N, Mowa CN, et al. Landiolol hydrochloride ameliorates acute lung injury in a rat model of early sepsis through the suppression of elevated levels of pulmonary endothelin-1. Life Sci. 2016 Dec 1;166:2733.

40. Lin D, Chai $Y$, Izadpanah R, Braun SE, Alt E. NPR3 protects cardiomyocytes from apoptosis through inhibition of cytosolic BRCA1 and TNF- $\alpha$. Cell Cycle Georget Tex. 2016 Sep 16;15(18):2414-9.

41. Mitaka C, Hirata Y, Nagura T, Tsunoda Y, Amaha K. Circulating endothelin-1 concentrations in acute respiratory failure. Chest. 1993 Aug;104(2):476-80.

42. Yanagisawa $M$, Kurihara $H$, Kimura $S$, Tomobe $Y$, Kobayashi $M$, Mitsui $Y$, et al. A novel potent vasoconstrictor peptide produced by vascular endothelial cells. Nature. 1988 Mar 31;332(6163):411-5.

43. Di Lisa F. A female way to protect the heart: say NO to calcium. Circ Res. 2006 Feb 17;98(3):298-300.

44. Sun J, Picht E, Ginsburg KS, Bers DM, Steenbergen C, Murphy E. Hypercontractile female hearts exhibit increased S-nitrosylation of the L-type Ca2+ channel alpha1 subunit and reduced ischemia/reperfusion injury. Circ Res. 2006 Feb 17;98(3):403-11.

45. Chen J, Chiazza F, Collino M, Patel NSA, Coldewey SM, Thiemermann C. Gender dimorphism of the cardiac dysfunction in murine sepsis: signalling mechanisms and age-dependency. PloS One. 2014;9(6):e100631.

46. Joulin O, Petillot $P$, Labalette $M$, Lancel S, Neviere R. Cytokine profile of human septic shock serum inducing cardiomyocyte contractile dysfunction. Physiol Res. 2007;56(3):291-7.

\section{Supplemental Digital Content Legends}

\section{Supplemental Digital Content 1: More details text}

Supplemental Digital Content 2: Experimental procedure. CLP: cecal ligation and puncture; MRI: magnetic resonance imaging; 31P MRS: 31P magnetic resonance spectroscopy. All rats were equipped with a right jugular catheter before experimental procedure. After surgery, all animals received a normal saline infusion $(10 \mathrm{~mL} / \mathrm{kg})$ for 30 minutes. 
Supplemental Digital Content 3: 31P magnetic resonance spectroscopy measurements of myocardial energy metabolism and pHi after 19 hours. Data are expressed as means \pm standard error of the mean (SEM). CLP: cecal ligation and puncture.

\section{Supplemental Digital Content 4: Effects of cecal ligation and puncture and landiolol on} expression levels of different genes after 20 hours. Data are expressed as average delta cycle threshold (deltaCT) and RPL32 is the housekeeping gene; the lower the deltaCT value, higher the expression. Data are expressed as means \pm standard error of the mean (SEM). Note that expression levels were calculated with only 4 biological replicates for genes annotated (4). CLP: cecal ligation and puncture; IL: interleukin; TNF-a: tumor necrosis factor alpha; Cox-2: cyclooxygenase 2; TREM1: triggering receptor expressed on myeloid cells 1; NR3C1: glucocorticoid receptor, NR3C2: mineralocorticoid receptor, ESR1: estrogen receptor; NPR: natriuretic peptide receptor; EDNRA: endothelin-1 receptor; AT1-AR: angiotensin type $1 \mathrm{~A}$ receptor; AT2-R: angiotensin type 2 receptor; AGTRAP: angiotensin II receptor associated protein; ADRB1: beta1-adrenoreceptor; PLN: phospholamban; ATP2A2: ATPase sarcoplasmic/endoplasmic reticulum Ca2+ transporting 2; RYR2: ryanodine receptor 2; cTNI: cardiac troponin I; eNOS: endothelial nitric oxide synthase; iNOS: inductible nitric oxide synthase.

${ }^{a} p<0.05$ vs. sham male and vs. sham female, respectively;

${ }^{b} p<0.05$ vs. CLP female;

${ }^{c} p<0.05$ vs. male of the equivalent group 

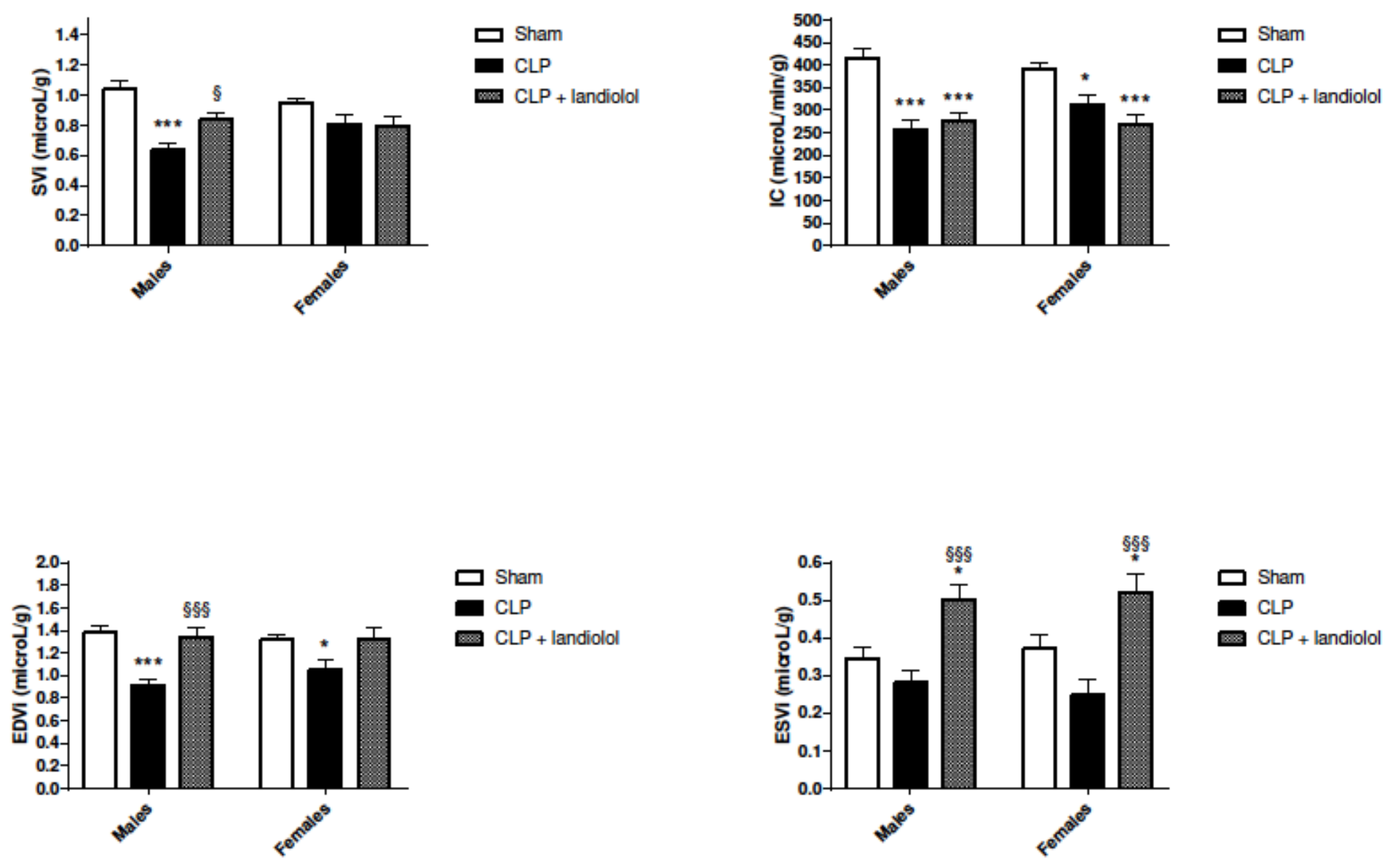

Figure 1: In vivo cardiac function using magnetic resonance imaging after 18 hours.

A: indexed stroke volume (SVi). B: Cardiac index (CI). C: Indexed end diastolic volume (EDVi).

D: Indexed end systolic volume (ESVi). Group mean value and standard error of the mean are represented. CLP: cecal ligation and puncture.

$* p<0.05, * * * p<0.001$ vs. sham male and vs. sham female, respectively

$\S p<0.05, \S \S \S p<0.001$ vs. CLP male and vs. CLP female, respectively 

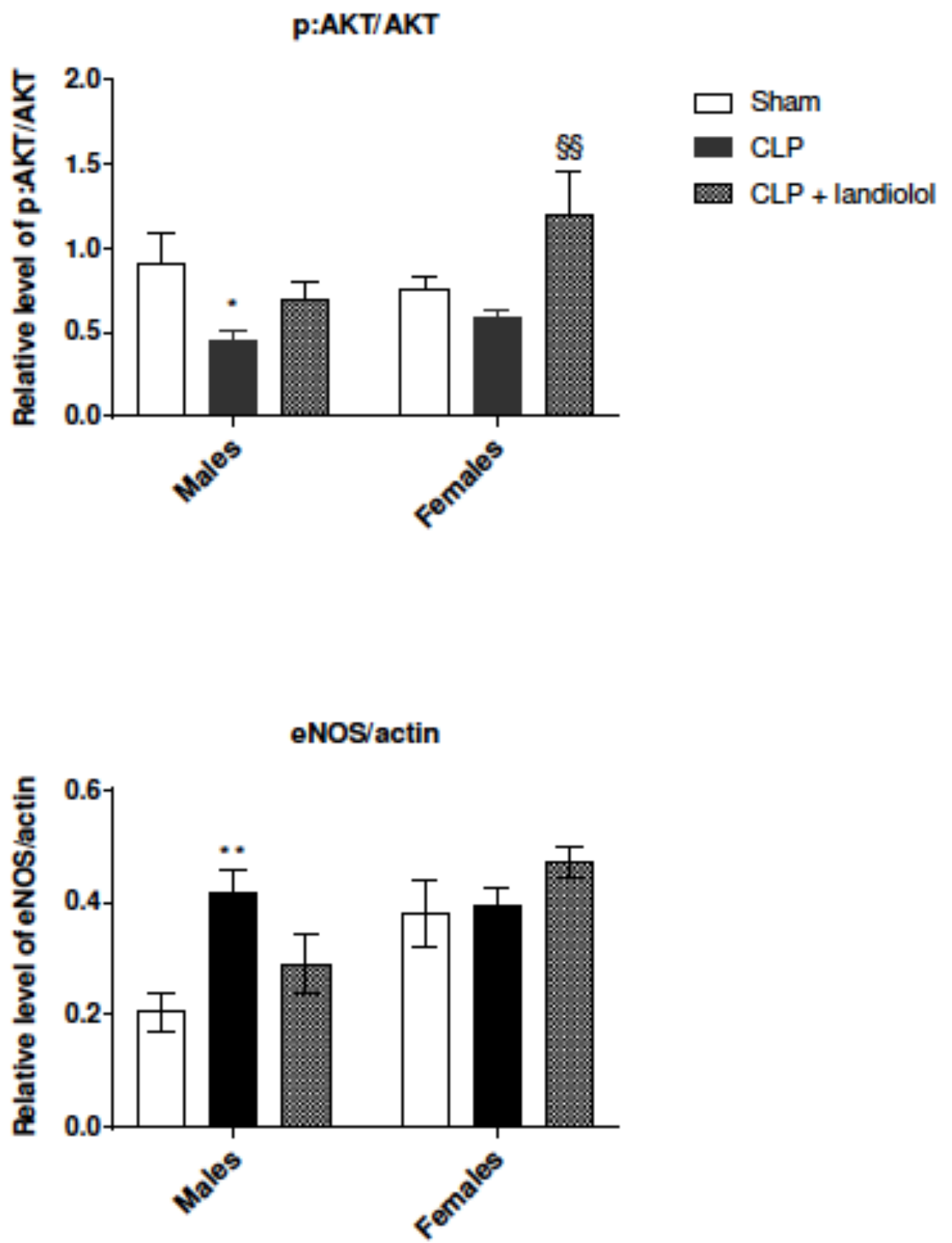

Figure 2: PAKT:AKT ratio and endothelial nitric oxide synthase (eNOS) expression using Western-blotting. 
Data are represented as means \pm standard error of the mean (SEM). CLP: cecal ligation and puncture

$* p<0.05, * * p<0.01$ vs. sham male

$\S \S p<0.01$ vs. CLP female

$+p<0.05$ vs. male of the equivalent group 


\begin{tabular}{|c|c|c|c|c|c|c|}
\hline & \multicolumn{3}{|c|}{ Males } & \multicolumn{3}{|c|}{ Females } \\
\hline & $\begin{array}{l}\text { Sham } \\
(n=6)\end{array}$ & $\begin{array}{l}\text { CLP } \\
(\mathrm{n}=8)\end{array}$ & $\begin{array}{l}\text { CLP + } \\
\text { landiolol } \\
(n=7)\end{array}$ & $\begin{array}{l}\text { Sham } \\
(n=7)\end{array}$ & $\begin{array}{l}\text { CLP } \\
(n=8)\end{array}$ & $\begin{array}{l}\text { CLP + } \\
\text { landiolol } \\
(n=7)\end{array}$ \\
\hline Initial weight (g) & $324 \pm 21$ & $304 \pm 13$ & $327 \pm 13$ & $227 \pm 10^{\dagger \dagger \dagger}$ & $225 \pm 6^{\dagger \dagger}$ & $212 \pm 7^{\dagger \dagger}$ \\
\hline $\begin{array}{l}\text { Weight variation } \\
(\%)\end{array}$ & $-0.9 \pm 1.3$ & $7.7 \pm 1.3^{* * *}$ & $2.4 \pm 0.6^{\S \S}$ & $-2.4 \pm 0.5$ & $5.3 \pm 1.2^{* * *}$ & $4.1 \pm 1^{* * *}$ \\
\hline $\begin{array}{l}\text { Temperature } \\
\left({ }^{\circ} \mathrm{C}\right)\end{array}$ & $36.3 \pm 0.3$ & $34.8 \pm 0.3^{* * *}$ & $35.8 \pm 0.2^{\S}$ & $36.4 \pm 0.1$ & $35.3 \pm 0.2^{* *}$ & $35.5 \pm 0.2^{*}$ \\
\hline HR (b/min) & $400 \pm 7$ & $404 \pm 9$ & $330 \pm 11^{* * *}, \S \S \S$ & $414 \pm 8$ & $388 \pm 14$ & $345 \pm 14^{* * *}, \S$ \\
\hline SBP (mmHg) & $137 \pm 5$ & $122 \pm 8$ & $113 \pm 7$ & $148 \pm 10$ & $145 \pm 9$ & $121 \pm 4^{*}$ \\
\hline DBP (mmHg) & $97 \pm 3$ & $89 \pm 7$ & $81 \pm 4$ & $107 \pm 7$ & $105 \pm 6$ & $79 \pm 3^{* *}, \S \S$ \\
\hline MBP (mmHg) & $115 \pm 3$ & $103 \pm 7$ & $97 \pm 6$ & $125 \pm 8$ & $123 \pm 7$ & $98 \pm 3^{* *}, \S$ \\
\hline $\begin{array}{l}\text { Lactatemia } \\
(\mathrm{mmol} / \mathrm{L})\end{array}$ & $4.1 \pm 0.2$ & $5.4 \pm 0.4$ & $4.4 \pm 0.4$ & $3.9 \pm 0.5$ & $5.0 \pm 0.6$ & $4.7 \pm 0.4$ \\
\hline
\end{tabular}

Table 1: Effects of CLP and landiolol on physiologic and hemodynamic variables after 18

hours. Weight variation: weight difference percentage between $\mathrm{HO}$ and $\mathrm{H} 18$; HR: heart rate; SBP: systolic blood pressure; DBP: diastolic blood pressure, MBP: mean blood pressure. Data are expressed as means \pm standard error of the mean (SEM).

$* \mathrm{p}<0.05, * * \mathrm{p}<0.01, * * * \mathrm{p}<0.001$ vs. sham male and vs. sham female, respectively $\S p<0.05, \S \S p<0.01, \S \S \S p<0.001$ vs. CLP male and vs. CLP female, respectively $+\dagger+p<0.001$ vs. male of the equivalent group 


\begin{tabular}{|c|c|c|c|c|c|c|}
\hline & \multicolumn{3}{|c|}{ Males } & \multicolumn{3}{|c|}{ Females } \\
\hline & $\begin{array}{l}\text { Sham } \\
(n=6)\end{array}$ & $\begin{array}{l}\text { CLP } \\
(\mathrm{n}=8)\end{array}$ & $\begin{array}{l}\text { CLP + } \\
\text { landiolol } \\
(n=7)\end{array}$ & $\begin{array}{l}\text { Sham } \\
(n=7)\end{array}$ & $\begin{array}{l}\text { CLP } \\
(n=8)\end{array}$ & $\begin{array}{l}\text { CLP }+ \\
\text { landiolol } \\
(\mathrm{n}=7)\end{array}$ \\
\hline SV $(\mu \mathbf{L})$ & $331 \pm 7$ & $191 \pm 16^{* * *}$ & $272 \pm 11^{*}, \S \S \S$ & $215 \pm 10^{\dagger \dagger}$ & $182 \pm 15$ & $167 \pm 15^{\dagger \dagger}$ \\
\hline $\mathrm{CO}(\mathrm{mL} / \mathrm{min})$ & $132 \pm 3$ & $77 \pm 7^{* * *}$ & $89 \pm 3^{* * *}$ & $89 \pm 5^{\dagger \dagger \dagger}$ & $70 \pm 6^{*}$ & $57 \pm 5^{* * *, \dagger \dagger}$ \\
\hline $\operatorname{EDV}(\mu \mathrm{L})$ & $442 \pm 18$ & $276 \pm 18^{* * *}$ & $434 \pm 18^{\S \S \S}$ & $300 \pm 16^{\dagger \dagger}$ & $238 \pm 22$ & $276 \pm 20^{\dagger \dagger}$ \\
\hline $\operatorname{ESV}(\mu \mathrm{L})$ & $112 \pm 13$ & $85 \pm 10$ & $162 \pm 11^{* *}, \S \S \S$ & $85 \pm 10$ & $56 \pm 9$ & $109 \pm 8^{\S \S, \dagger}$ \\
\hline LVEF (\%) & $75 \pm 2$ & $69 \pm 4$ & $63 \pm 2^{* *}$ & $72 \pm 2$ & $77 \pm 2$ & $60 \pm 2^{* *}, \S \S$ \\
\hline$W t_{\text {dia }}(\mathbf{m m})$ & $1.55 \pm 0.04$ & $1.83 \pm 0.09^{*}$ & $1.54 \pm 0.05^{\S \S}$ & $1.39 \pm 0.02$ & $1.60 \pm 0.06^{\dagger}$ & $1.49 \pm 0.09$ \\
\hline $\mathrm{Wt}_{\text {sys }}(\mathrm{mm})$ & $2.67 \pm 0.08$ & $2.82 \pm 0.11$ & $2.29 \pm 0.06^{*}, \S \S \S$ & $2.46 \pm 0.1$ & $2.71 \pm 0.1$ & $2.14 \pm 0.06^{\S \S \S}$ \\
\hline sWtn (\%) & $73 \pm 5$ & $55 \pm 5$ & $50 \pm 5^{*}$ & $76 \pm 5$ & $69 \pm 4$ & $46 \pm 7^{* * *}, \S \S$ \\
\hline $\begin{array}{l}\text { MBF } \\
(\mathrm{mL} / \mathrm{g} / \mathrm{min})\end{array}$ & $7.40 \pm 0.92$ & $7.87 \pm 0.84$ & $8.20 \pm 0.52$ & $7.00 \pm 0.85$ & $6.91 \pm 0.64$ & $7.02 \pm 1.01$ \\
\hline
\end{tabular}

Table 2: In vivo cardiac function using MRI after 18 hours. EDV: end-diastolic volume; ESV: end-systolic volume; SV: stroke volume; CO: cardiac output; LVEF: left ventricular ejection fraction; Wtdia: mean wall thickness in diastole; Wtsys: mean wall thickness in systole; sWtn: systolic wall thickening; MBF: myocardial blood flow. Data are expressed as means \pm standard error of the mean (SEM).

$* p<0.05, * * p<0.01, * * * p<0.001$ vs. sham male and vs. sham female, respectively $\S \S p<0.01, \S \S \S p<0.001$ vs. CLP male and vs. CLP female, respectively $+p<0.05,+\dagger p<0.01,++\dagger p<0.001$ vs. male of the equivalent group 


\begin{tabular}{|c|c|c|c|c|c|c|}
\hline & \multicolumn{3}{|c|}{ Males } & \multicolumn{3}{|c|}{ Females } \\
\hline & $\begin{array}{l}\text { Sham } \\
(n=6)\end{array}$ & $\begin{array}{l}\text { CLP } \\
(n=6)\end{array}$ & $\begin{array}{l}\text { CLP }+ \\
\text { landiolol } \\
(\mathrm{n}=7) \\
\end{array}$ & $\begin{array}{l}\text { Sham } \\
(n=5)\end{array}$ & $\begin{array}{l}\text { CLP } \\
(n=6)\end{array}$ & $\begin{array}{l}\text { CLP + landiolol } \\
(n=7)\end{array}$ \\
\hline $\begin{array}{l}\text { Heart weight } \\
\text { (g) }\end{array}$ & $0.97 \pm 0.05$ & $0.90 \pm 0.03$ & $0.91 \pm 0.03$ & $0.72 \pm 0.04^{\dagger \dagger}$ & $0.71 \pm 0.02^{\dagger \dagger}$ & $0.64 \pm 0.01^{\dagger \dagger \dagger}$ \\
\hline $\begin{array}{l}\text { Ratio heart / } \\
\text { body weight } x \\
1000\end{array}$ & $3.03 \pm 0.11$ & $2.81 \pm 0.11$ & $2.74 \pm 0.06$ & $3.23 \pm 0.07$ & $3.01 \pm 0.09$ & $2.94 \pm 0.15$ \\
\hline $\begin{array}{l}\text { HR isolated } \\
\text { heart }(\mathrm{b} / \mathrm{min})\end{array}$ & $306 \pm 27$ & $331 \pm 33$ & $298 \pm 18$ & $302 \pm 19$ & $337 \pm 16$ & $247 \pm 30$ \\
\hline LVDP (mmHg) & $77 \pm 6$ & $47 \pm 3^{* * *}$ & $61 \pm 4$ & $74 \pm 5$ & $47 \pm 5^{* *}$ & $60 \pm 18$ \\
\hline $\begin{array}{l}\text { RPP } \\
(\mathrm{mmHg} / \mathrm{min})\end{array}$ & $22961 \pm 1115$ & $15733 \pm 2035^{* *}$ & $17876 \pm 962^{*}$ & $22141 \pm 1746$ & $15678 \pm 1129^{*}$ & $13705 \pm 1373^{* * *}$ \\
\hline $\begin{array}{l}\text { Coronary } \\
\text { flow indexed } \\
(\mathrm{mL} / \mathrm{min} / \mathrm{g})\end{array}$ & $18 \pm 0.8$ & $17.5 \pm 0.9$ & $18.4 \pm 1.2$ & $15.2 \pm 2.5$ & $12.5 \pm 1.1^{\dagger}$ & $16.7 \pm 0.9$ \\
\hline
\end{tabular}

Table 3: Ex vivo assessment using isolated heart rat preparation after 19 hours. HR: Heart rate; LVDP: Left ventricular developed pressure; RPP: Rate pressure product (LVDP $x$ HR). Data are expressed as means \pm standard error of the mean (SEM).

${ }^{*} \mathrm{p}<0.05,{ }^{* *} \mathrm{p}<0.01,{ }^{* * *} \mathrm{p}<0.001$ vs. sham male and vs. sham female respective $+p<0.05,++\dagger p<0.001$ vs. male of the equivalent group 